\title{
Laparoscopic Hiatal Hernia Repair in Patients with an Intrathoracic Pancreas: Case Series and a Review of Literature
}

\author{
Robert C. Tolboom ${ }^{1,2,3}$, Paul J. Wijsman ${ }^{1}$, Ivo Broeders ${ }^{1}$, Werner A. Draaisma ${ }^{4}$ \\ 1. Surgery, Meander Medical Center, Amersfoort, NLD 2. Anesthesiology, Radboud University Medical Center \\ (Radboudumc), Nijmegen, NLD 3. Robotics and Mechatronics, University of Twente, Enschede, NLD 4. Surgery, Jeroen \\ Bosch Hospital, Den Bosch, NLD
}

Corresponding author: Werner A. Draaisma,w.draaisma@jbz.nl

\begin{abstract}
Transhiatal herniation of the pancreas is rare with only 17 cases reported in 25 years. Presentation of pancreatic herniation is diverse. In the majority of cases, the pancreatic herniation is found incidentally on CT-scans made for evaluating complaints related to a large or giant hiatal hernia. We present a literature review and case series of three patients with symptomatic type IV hiatal hernia with incidental, asymptomatic pancreatic herniation. All cases were managed laparoscopically with robotic assistance.
\end{abstract}

Received 12/30/2019

Review began 01/21/2020 Review ended 02/24/2020 Published 02/28/2020

(c) Copyright 2020

Tolboom et al. This is an open access article distributed under the terms of the Creative Commons Attribution License CC-BY 4.0., which permits unrestricted use, distribution, and reproduction in any medium, provided the original author and source are credited.
Categories: Cardiac/Thoracic/Vascular Surgery, General Surgery, Anatomy Keywords: thoracic, pancreas, hiatal hernia, type iv, pancreatic herniation

\section{Introduction}

Hiatal hernia is either congenital or acquired. Acquired hiatal hernia can be classified based upon the position of the gastro-esophageal junction and the extent of herniation. The most common (95\%) hernia is a type I or sliding hernia. In these hernias only the gastro-esophageal (GE) junction is herniated into the chest. A type II hernia is characterized by herniation of the gastric fundus into the mediastinum adjacent to the esophagus with the GE-junction still in the correct position. In type III (mixed) hiatal hernia, at least $30 \%$ of the stomach is herniated along with the GE-junction [1,2]. Only a type IV giant hiatal hernia $(0.3 \%)$ and congenital hernias $(0.2 \%)$ are characterized by herniation of additional organs besides the stomach. The most frequently herniated organs are the colon, small intestine, omentum, or spleen $[3,4]$.

While small hiatal hernia is common and often without symptoms, large and giant hiatal hernias are less frequently seen and may present themselves with a myriad of complaints ranging from gastro-esophageal reflux and regurgitation to symptoms of heart failure due to cardio-pulmonary compression [1]. Though intraperitoneal organs such as the transverse colon sometimes herniate along with the stomach, herniation of the pancreas is very rare.

We present a series of three patients with pancreatic herniation, and discuss all available literature in order to advise on (surgical) management of this rare condition.

\section{Case Presentation}

\section{Patient A}

A 74-year-old woman with a history of ischemic stroke, transabdominal uterus extirpation and left inguinal hernia repair was referred for outpatient evaluation after several years of dyspnea, dyspepsia, vomiting and thoracic pain. Laboratory studies were within normal limits. Computed tomography (CT) examination showed herniation of the stomach and pancreas through the esophageal hiatus (Figure 1) without any pancreatic pathologic findings or signs of inflammation. Esophagogastroduodenoscopy excluded the presence of esophagitis. 


\section{Cureus}

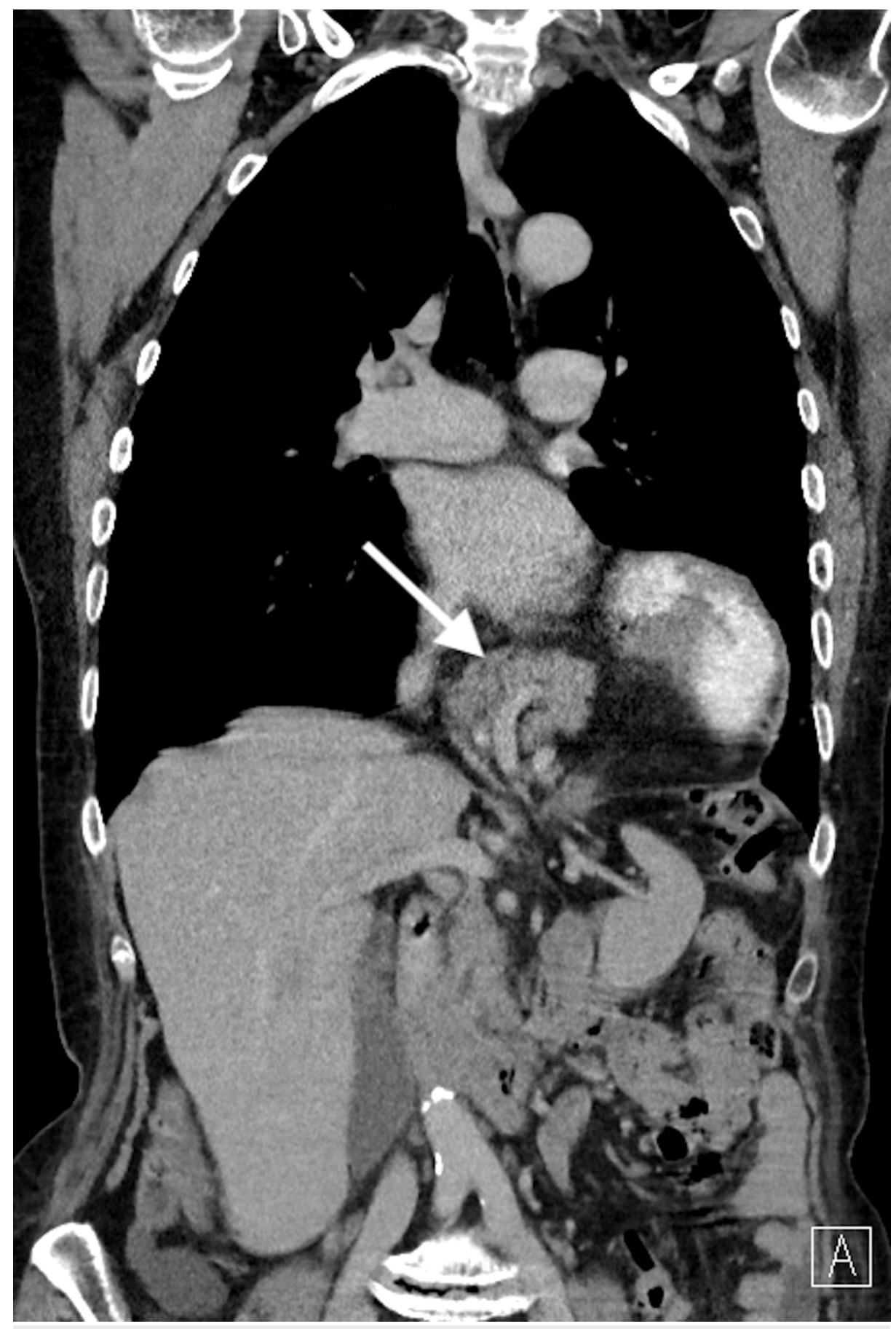

FIGURE 1: CT-scan of Patient A depicting herniation of the pancreas into the thoracic cavity.

With the diagnosis of a symptomatic type IV (giant) hiatal hernia, an elective robot-assisted laparoscopic surgery was planned. After intubation, the patient was placed in a reverse Trendelenburg and French position with both arms extended. Five ports were used and introduced in a smiley-face configuration. The da Vinci robot was docked from over the head. Several adhesions were taken down followed by introduction of an endopaddle to retract the left lateral segment of the liver superiorly. Using a hook cautery, the hiatus was successfully dissected. The stomach and pancreas could easily be repositioned intra-abdominally after which the crus was closed with two posterior sutures, followed by one anteriorly. All stitches were reinforced with $1 \times 1 \mathrm{~cm}$ polypropylene pledgets. To conclude the procedure, an anterior fundoplication was made. The total duration of the uncomplicated procedure was 90 minutes.

The postoperative course was uneventful and the patient was discharged on the fifth postoperative day. Two years after surgery, the patient developed a spontaneous recurrent hiatal hernia with complaints of dyspnea 


\section{Cureus}

which was corrected, and a pyloromyotomy was performed because of gastric emptying disorders seen on fasted computed tomography scan. Three years after surgery, she is in good condition, with limited dyspeptic symptoms.

\section{Patient B}

A 66-year-old woman with a history of a laparoscopic cholecystectomy was referred for outpatient evaluation due to progressive complaints of pressure on the chest and shortness of breath after exertion without chest pain. These complaints gradually worsened in a period of two years to the point where the patient was no longer able to walk, ride her bike or sing. She also suffered from dyspepsia. A CT-scan revealed a giant hiatal hernia with complete intrathoracic stomach, transverse colon and pancreas (Figure 2).

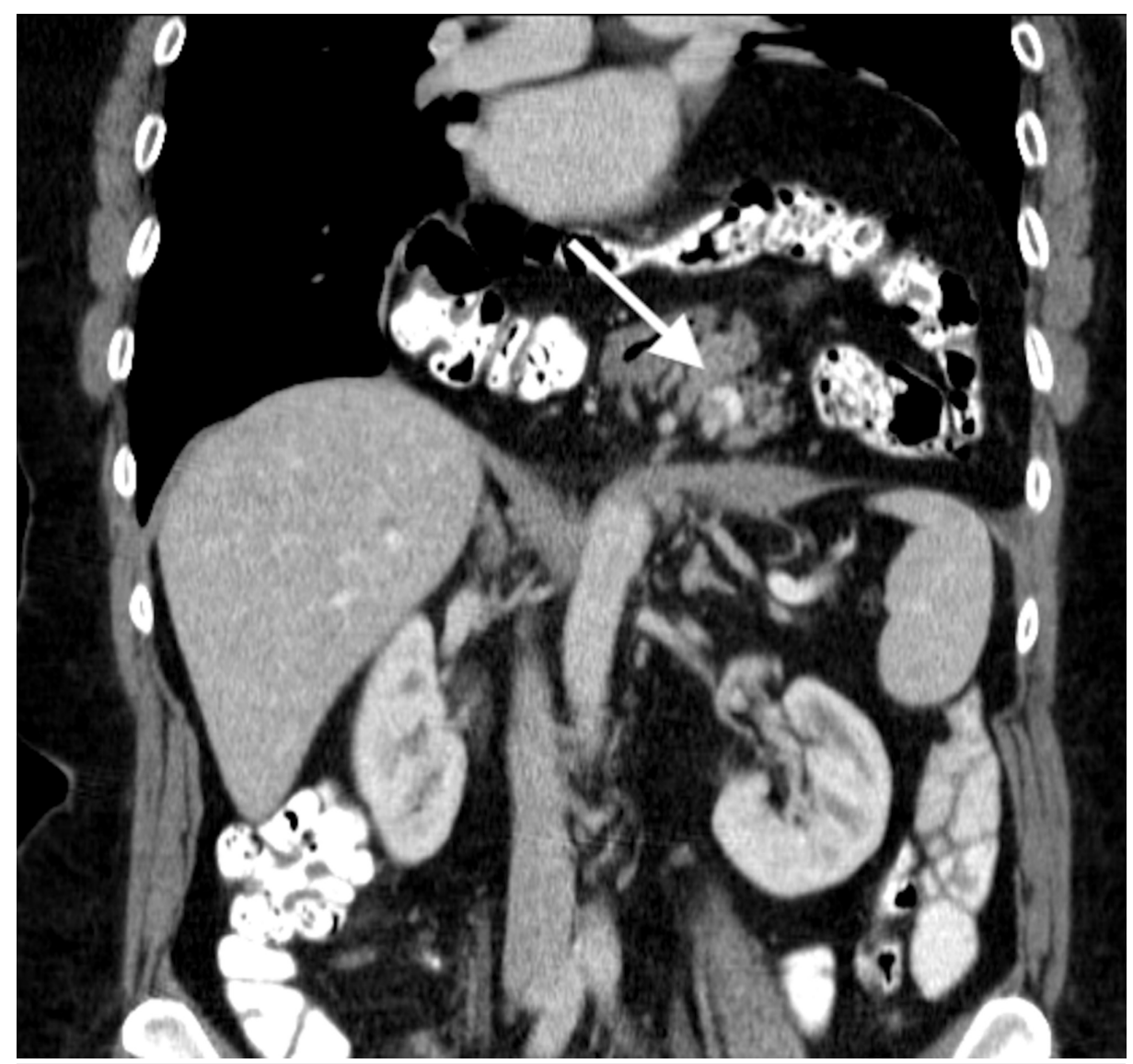

FIGURE 2: CT-scan of Patient B depicting herniation of the pancreas into the thoracic cavity.

An elective robot-assisted laparoscopic hiatal hernia repair was planned. After crural dissection, the stomach, transverse colon and pancreas were reduced. Due to the hernia's size, lateral incisions were necessary before a PROCEED ${ }^{\circledR}$ mesh-reinforced crural closure could be attempted. With the lateral incision, the thoracic cavity was opened. This defect was later bridged using a moon-shaped PROCEED ${ }^{\circledR}$ surgical mesh using V-Loc sutures. Due to expected pleural effusion, a chest drain was placed. After crural closure, an anterior fundoplication was made. Duration of surgery was 135 minutes.

The post-operative course was uneventful. The chest drain was removed the first post-operative day, and the patient discharged on the fourth. At long-term follow-up, all complaints were resolved.

\section{Patient C}

A 42-year-old woman with a history of a transvaginal hysterectomy, laparoscopic cholecystectomy, epilepsy and chronic depression was referred to our outpatient clinic due to complaints of nausea, recurrent vomiting, abdominal and retrosternal pain and dyspepsia. Laboratory studies were within normal limits. A CT-scan showed a large hiatal hernia (>7 cm) with intrathoracic stomach, colon and pancreas (Figure 3). 


\section{Cureus}

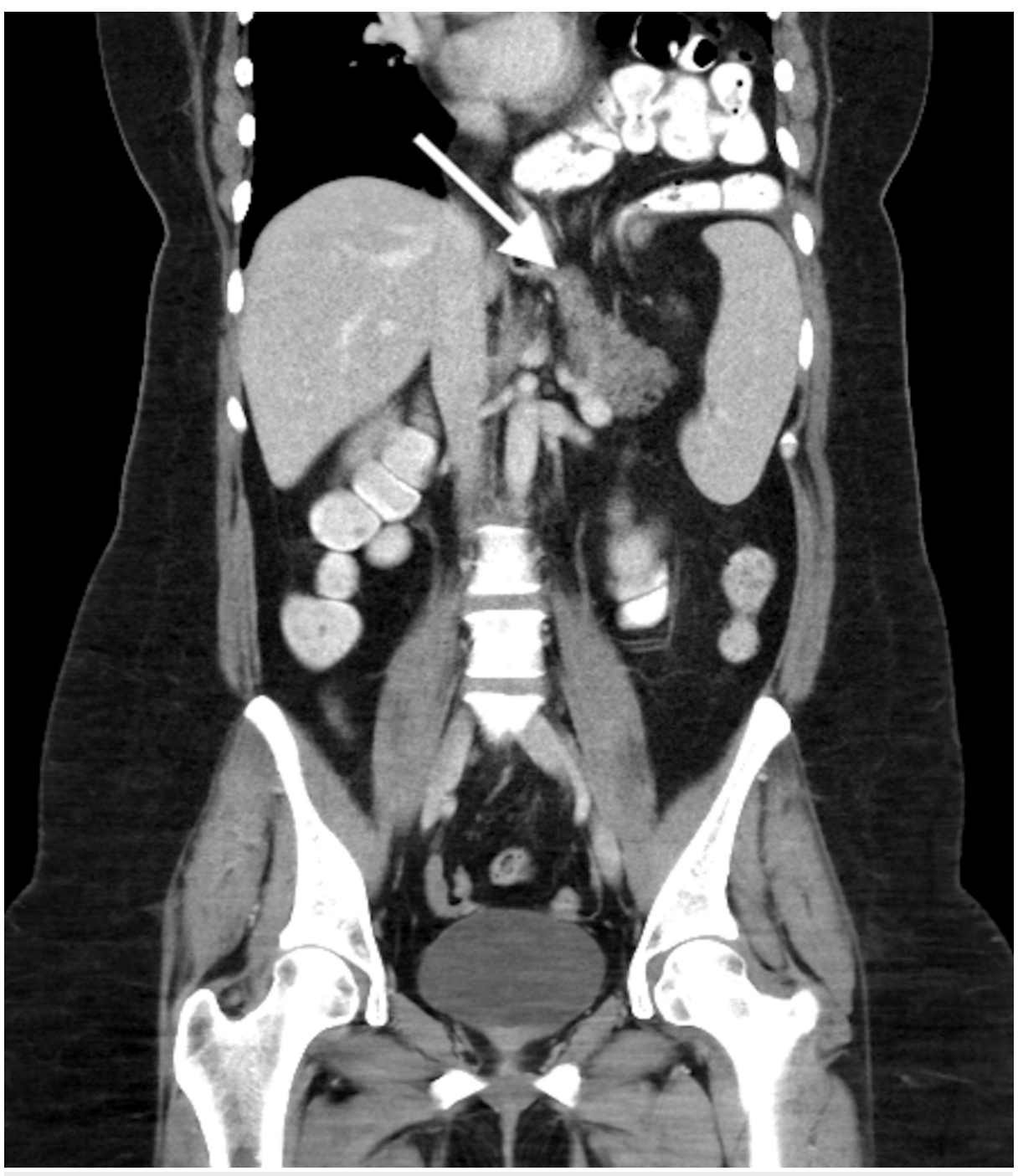

FIGURE 3: CT-scan of Patient C depicting herniation of the pancreas into the thoracic cavity.

In an elective robot-assisted laparoscopic hiatal hernia repair lasting 110 minutes, the stomach, pancreas and colon were reduced. The crus was closed with two stitches posteriorly and three stitches anteriorly, followed by anterior partial fundoplication.

After an uneventful postoperative course, the patient was discharged on the seventh post-operative day. At long-term follow-up she had moderate dyspeptic symptoms. No signs of recurrent hiatal hernia were seen on follow-up CT scans.

\section{Discussion}

The pancreas is formed in the dorsal mesoduodenum from the endodermal germ layer and will be positioned in the dorsal mesogastrium at the end of the fifth gestational week. Meanwhile, the stomach rotates and grows disproportionately. By rotating about the longitudinal axis, the dorsal mesogastrium is pulled to the left, creating a space behind the stomach called omental bursa (or lesser peritoneal sac). This rotation also pulls the ventral mesogastrium to the right. With continued rotation of the stomach, the dorsal mesogastrium lengthens, and partly fuses with the peritoneum of the posterior abdominal wall. The tail of the pancreas lies against this region. After degeneration of the posterior leaf of the dorsal mesogastrium and peritoneum of the posterior body wall along the line of fusion, the pancreatic tail is covered by peritoneum on the anterior surface only and therefore lies in a retroperitoneal position [5].

When the colon and small intestine are herniated, stretching of transverse mesocolon may allow mobilization of the pancreas after lengthening of the posterior adhering fascia [2,6]. In a recent human cadaver study, researchers found retropancreatic fascia lining the posterior aspect of the body of the pancreas but were unable to locate the anterior renal fascia, possibly due to degeneration of the adrenal 


\section{Cureus}

gland with ageing [7]. It is likely that in the elderly the pancreas is more mobile due to connective tissue degeneration, and therefore more prone to migrating through a large hiatal hernia [7].

In the last 25 years, 17 cases of intrathoracic herniation of (parts of) the pancreas have been reported (Table 1) $[2-4,6,8-20]$. In the majority of cases, the pancreatic herniation itself was asymptomatic and found incidentally $[2,4,8-12,16-20]$ on CT-scans made for evaluating complaints befitting a large or giant hiatal hernia such as abdominal pain [4,10,11,16-19], vomiting [17,18], dysphagia [4] or dyspnea [2,16,20]. Five cases, however, were diagnosed with pancreatitis secondary to intrathoracic pancreatic herniation [3,6,1315], one of which was associated with pancreatic torsion [6].

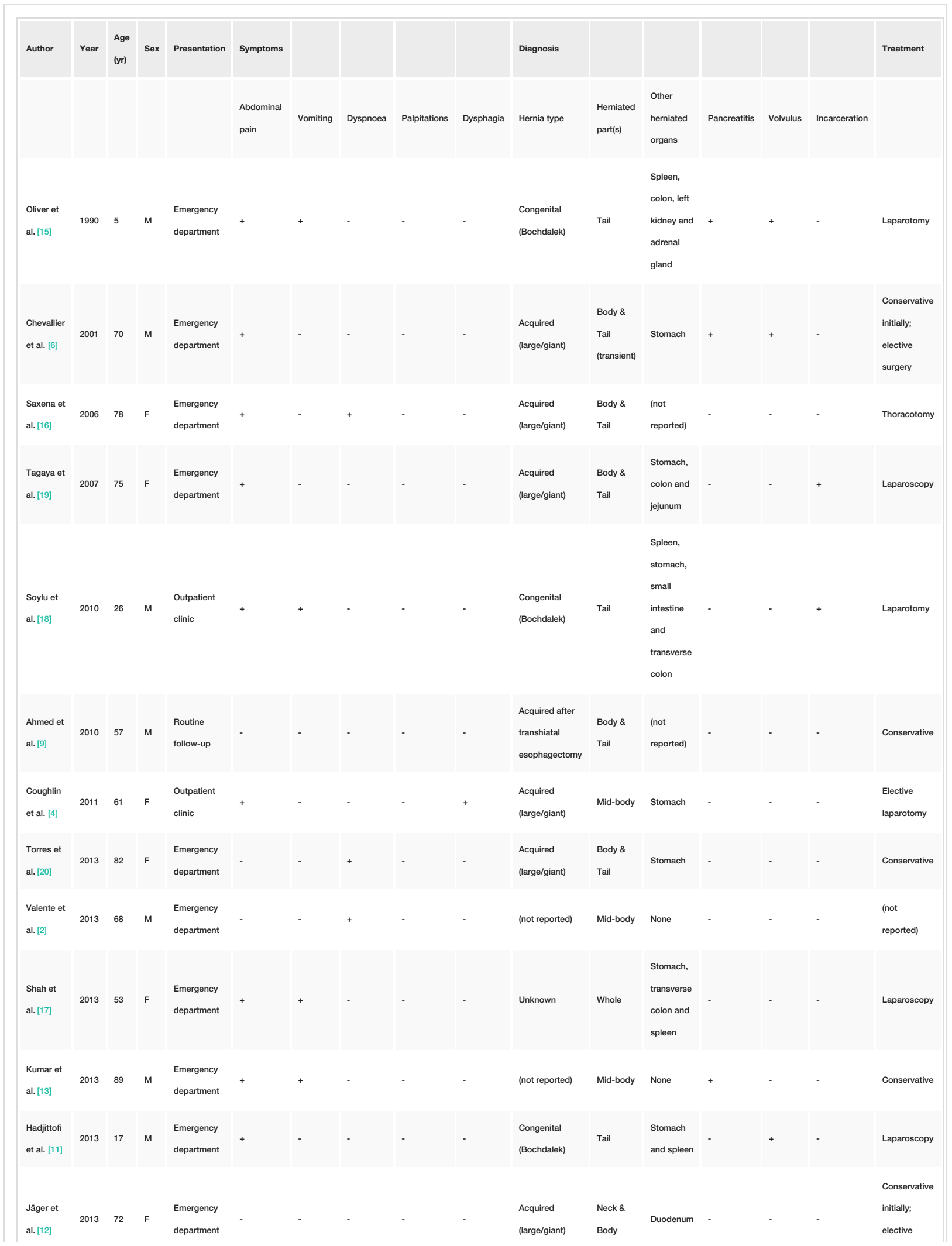




\section{Cureus}

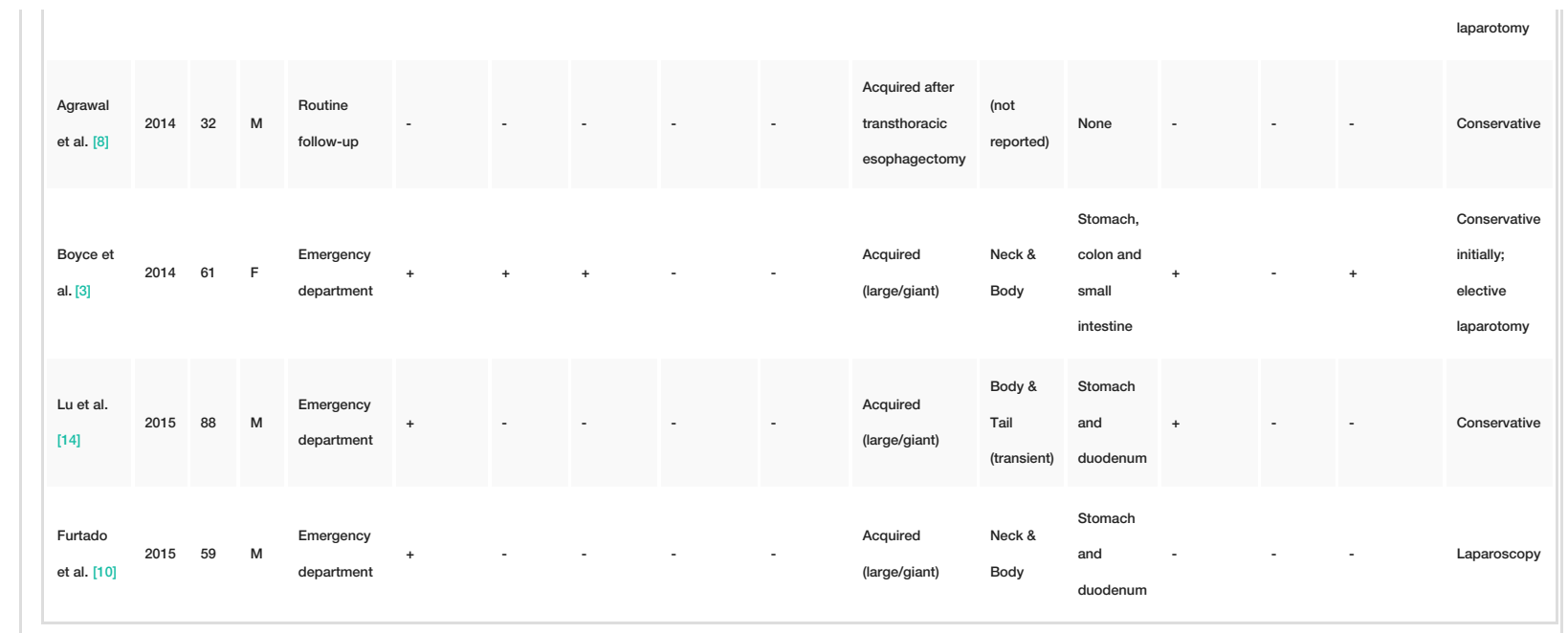

TABLE 1: Literature review: transhiatal pancreatic herniation.

While pancreatitis is known to occur as a result of pancreatic herniation, large and giant hiatal hernia without pancreatic involvement may also present with acute or recurrent pancreatitis. The underlying mechanism is believed to be that of intermittent ischemia due to traction on the vascular pedicle $[3,14,15]$, repetitive trauma associated with pancreatic movement across the hernia [3] or torsion with occlusion of the main pancreatic duct [6].

Pancreatic herniation may occur in patients with many different kinds of hiatal hernia. They have been reported in congenital $[11,15,18]$ and acquired hernias $[3,4,6,10,12,14,16,19,20]$, but also as rare long-term complication after both transhiatal and transthoracic esophagectomy [8,9]. Even isolated (possibly congenital) herniation of just the pancreas [2] and transient pancreatic herniation have been reported $[6,14]$.

Treatment decisions should be made based upon patient presentation, type of hiatal hernia and herniated organs. All symptomatic hiatal hernias may be considered for surgery while completely asymptomatic acquired hiatal hernia with herniation of one or more organs including the pancreas may be managed conservatively with watchful waiting. In case of presentation with acute or recurrent pancreatitis, delayed surgery should be attempted due to an increased morbidity and mortality associated with the systemic inflammatory response.

The approaches available for reduction of the herniated organs and hiatal hernia repair include transthoracic, transabdominal, and laparoscopic. In our case series we demonstrate that in the absence of pancreatitis, large and giant hiatal hernia with pancreatic involvement may be safely managed laparoscopically (possibly with robotic assistance). Two patients in this small series had persistent dyspeptic symptoms. This might be related to the extensive dissection and stretching of the retracted esophagus, and damage to vagal nerve branches despite the meticulous dissection to avoid nerve disruption or thermal damage.

\section{Conclusions}

This case series adds to the existing evidence that laparoscopic surgery for giant hiatal hernia with herniation of the pancreas is feasible and safe, allowing patients to quickly resume their daily activities.

\section{Additional Information}

\section{Disclosures}

Human subjects: Consent was obtained by all participants in this study. Conflicts of interest: In compliance with the ICMJE uniform disclosure form, all authors declare the following: Payment/services info: All authors have declared that no financial support was received from any organization for the submitted work. Financial relationships: All authors have declared that they have no financial relationships at present or within the previous three years with any organizations that might have an interest in the submitted work. Other relationships: All authors have declared that there are no other relationships or activities that could appear to have influenced the submitted work.

\section{References}

1. Loffeld RJ, van der Putten AB: Newly developing hiatus hernia: a survey in patients undergoing upper 
gastrointestinal endoscopy. J Gastroenterol Hepatol. 2002, 17:542-544. 10.1046/j.1440-1746.2002.02720.x

2. Valente T, Rossi G, Lassandro F, Rea G, Muto M: Asymptomatic isolated partial hiatal herniation of the pancreas: MDCT evaluation and anatomical explanation: case report and review of literature. Clin Anat. 2013, 26:1008-1013. 10.1002/ca.22240

3. Boyce K, Campbell W, Taylor M: Acute pancreatitis secondary to an incarcerated paraoesophageal hernia: a rare cause for a common problem. Clin Med Insights Case Rep. 2014, 7:25-27. 10.4137/CCRep.S13079

4. Coughlin M, Fanous M, Velanovich V: Herniated pancreatic body within a paraesophageal hernia . World J Gastrointest Surg. 2011, 3:29-30. 10.4240/wjgs.v3.i2.29

5. Sadler TW: Langman's Medical Embryology, 9th edition. Langman J (ed): Lippincott Williams \& Wilkins, Philadelphia; 2004.

6. Chevallier P, Peten E, Pellegrino C, Souci J, Motamedi JP, Padovani B: Hiatal hernia with pancreatic volvulus: a rare cause of acute pancreatitis. Am J Roentgenol. 2001, 177:373-374. 10.2214/ajr.177.2.1770373

7. Yang JD, Ishikawa K, Hwang HP, et al.: Retropancreatic fascia is absent along the pancreas facing the superior mesenteric artery: a histological study using elderly donated cadavers. Surg Radiol Anat. 2013, 35:403-410. 10.1007/s00276-012-1051-7

8. Agrawal N, Pal S, Dash NR, Madhusudhan K, Srivastava DN: Asymptomatic transhiatal pancreatic herniation after oesophagectomy. J Clin Diagn Res. 2014, 8:24-25. 10.7860/JCDR/2014/9881.5017

9. Ahmed S, Fontaine JP, Ng T: Pancreatic herniation after transhiatal esophagectomy. Ann Thorac Surg. 2010, 89:308-309. 10.1016/j.athoracsur.2009.05.087

10. Furtado RV, D'Netto TJ, Hook HC, Falk GL, Vivian S: Massive hiatus hernia complicated by jaundice . J Surg Case Rep. 2015, 2015:rjv087. 10.1093/jscr/rjv087

11. Hadjittofi C, Matter I, Eyal O, Slijper N: Laparoscopic repair of a late-presenting Bochdalek diaphragmatic hernia with acute gastric volvulus. BMJ Case Rep. 2013, 2013:bcr2013008990. 10.1136/bcr-2013-008990

12. Jager T, Neureiter D, Nawara C, Dinnewitzer A, Ofner D, Lamade W: Intrathoracic major duodenal papilla with transhiatal herniation of the pancreas and duodenum: a case report and review of the literature. World J Gastrointest Surg. 2013, 5:202-206. 10.4240/wjgs.v5.i6.202

13. Kumar P, Turp M, Fellows S, Ellis J: Pancreatic herniation: a rare cause of acute pancreatitis? . BMJ Case Rep. 2013, 2013:bcr2013201979. 10.1136/bcr-2013-201979

14. Lu LX, Payne M, Theobald CN: Gastroenterology: diaphragmatic herniation and pancreatitis . J Gastroenterol Hepatol. 2015, 30:653. 10.1111/jgh.12880

15. Oliver MJ, Wilson AR, Kapila L: Acute pancreatitis and gastric volvulus occurring in a congenital diaphragmatic hernia. J Pediatr Surg. 1990, 25:1240-1241. 10.1016/0022-3468(90)90516-C

16. Saxena P, Konstantinov IE, Koniuszko MD, Ghosh S, Low VH, Newman MA: Hiatal herniation of the pancreas: diagnosis and surgical management. J Thorac Cardiovasc Surg. 2006, 131:1204-1205. 10.1016/j.jtcvs.2006.01.008

17. Shah N, Fernandes R, Thakrar A, Rozati H: Diaphragmatic hernia: an unusual presentation. BMJ Case Rep. 2013, 2013:bcr2013008699. 10.1136/bcr-2013-008699

18. Soylu E, Junnarkar S, Kocher HM: Recurrent indigestion in a young adult . Case Rep Gastroenterol. 2010, 4:518-523. 10.1159/000322871

19. Tagaya N, Tachibana M, Kijima H, Kakihara Y, Hamada K, Sawada T, Kubota K: Laparoscopic treatment of paraesophageal hiatal hernia with incarceration of the pancreas and jejunum. Surg Laparosc Endosc Percutan Tech. 2007, 17:313-316. 10.1097/SLE.0b013e318059bf50

20. Torres D, Parrinello G, Cardillo M, Bellanca M, Licata G: Hiatal herniation of the stomach and pancreas in a patient with oxygen desaturations. Libyan J Med. 2013, 8:23288. 10.3402/ljm.v8i0.23288 